\title{
A Study of Self-Perceived Competence of Medical Interns in India
}

\author{
Dr. Harish Chander Bandhu ${ }^{1}$, Dr. Seema Dutt Bandhu ${ }^{2 *}$, Dr. Swati Raje ${ }^{3}$, Dr. Gaganpreet Singh ${ }^{4}$ \\ ${ }^{1}$ MD, Professor and Head, Department of Obstetrics and Gynaecology, Andaman and Nicobar Institute of Medical \\ Sciences, Pant Hospital, Old Ayush Building, Near DHS Annexe Building Near Rear Gate Of G.B, Atlanta Point, Port \\ Blair, Andaman and Nicobar Islands 744104, India \\ ${ }^{2} \mathrm{MD}$, Professor and Head, Department of Ophthalmology, Punjab Institute of Medical Sciences, Garha Rd, Jalandhar, \\ Punjab 144006, India \\ ${ }^{3} \mathrm{PhD}$ (Statistics), Maharashtra Institute of Medical Sciences and Research, Talegaon Dabhade Pune, Maharashtra, India \\ ${ }^{4}$ Junior Resident, Department of Ophthalmology, Punjab Institute of Medical Sciences, Garha Rd, Jalandhar, Punjab \\ 144006, India
}

\section{*Corresponding Author}

Dr. Seema Dutt Bandhu

\author{
Article History \\ Received: 27.07 .2020 \\ Accepted: 05.08 .2020 \\ Published: 07.08 .2020
}

\begin{abstract}
Introduction: Internship is the period when a medical graduates acquires skills which enables him/her to become an effective physician of first contact of the community. However, new graduates go through this period only preparing for the post graduate entrance exam without acquiring many skills and practical knowledge. We conducted a cross-sectional study to document the self-perceived competence of the interns in performing the basic medical skills. Materials and Methods: This was a cross-sectional study conducted on 70 medical interns graduating from a private medical college in North India. The interns who were willing to participate in the study were asked to state the level of their competence on a 3-point scale in a 95 point questionnaire. The questionnaire was divided as per clinical specialties and further sub-divided into competence in examination skills, core skills and knowledge, attitude and performance skills. Results: All the interns self-rated that they were competent in recording basic clinical variables, $60 \%$ percent students self-rated that they were fully competent in examination skills and core competencies of internal medicine but only $37.14 \%$ felt competent in knowledge and attitudinal skills. In surgery, more than $60 \%$ interns rated themselves to have good core competencies, $37.14 \%$ rated themselves to be competent in examination of surgical patients whereas only $28 \%$ interns rated themselves as competent in knowledge and attitudinal skills of surgery. Only one third interns selfrated that they had good examination skills pertaining to ENT and Ophthalmology. Similarly less than $20 \%$ interns selfrated that they were good at core competencies related to Ophthalmology and ENT departments. Conducting a normal vaginal delivery was considered a core competency of Ob-Gyn (Obstetrics and Gynaecology) department. Only 12 interns (27.8\%) self-rated to be fully competent to do so, 51.4\% interns self-rated that they had good examination skills and only $10 \%$ interns felt competent in knowledge and attitudinal skills of Ob-Gyn. Majority of the students rated themselves as having good examination skills and core competencies in pediatrics. Discussion: In the present study less than $60 \%$ interns rated themselves as competent in examination skills and core competencies in major clinical specialities except in Ob-gyn, while less than ten percent $(9.3 \%)$ self evaluated their examination skills as poor. This implies that many of the graduates did not feel competent to carry out the role of a junior doctor with confidence. A variety of studies from other countries have found that many graduates feel inadequately prepared for the role of junior doctor [11-13] and criticisms that medical schools do not prepare graduates for early medical practice have been voiced many times. Conclusions: All the graduate medical doctors are not fully competent to perform the basic medical and surgical procedures. They are especially lacking in knowledge and attitudinal skills so medical educators need to stress on training the graduates in knowledge application and critical thinking.
\end{abstract}

Keywords: Competent, Skills, Internship.

\section{INTRODUCTION}

In a geographically diverse and developing country like India, a large population is dependent for the basic health services at community level health centers. To be able to manage a health center independently, a medical

Copyright @ 2020: This is an open-access article distributed under the terms of the Creative Commons Attribution license which permits unrestricted use, distribution, and reproduction in any medium for non commercial use (NonCommercial, or CC-BY-NC) provided the original author and source are credited. 
graduate must have the knowledge and skills to conduct the out-patient department, carry out basic medical and surgical procedures and provide first aid for medical and surgical emergencies. Internship is the period in which a medical graduate applies his/her knowledge in practical situations and gradually acquires skills under supervision so that at the end of the training, he is efficient enough to manage a basic health care facility independently. Moreover, the basic knowledge and skills acquired during internship form the foundation for acquiring enhanced knowledge and skills during post-graduation.

The Medical Council of India, in 2010, published Vision 2015 [1]. The document describes the "Indian Medical Graduate" as a 'physician of first contact of the community while being globally relevant [2]. However, there has been a frequently stated sentiment regarding diminishing skills and the ability to "perform" among graduates in recent years. Concerns about this inadequacy have been widely expressed in the literature [3-5]. The situation in India is primarily because of the postgraduate admission test conducted at the end of internship, which is a written exam without any test for skills. The internship period, which is primarily meant for skill development, is spent in preparation for a high-stakes entrance exam. Various strategies to make the internship period more meaningful have been suggested [5, 6].

We conducted a cross- sectional study to know the self perceived competence of interns at the end of the internship period to study the gap between the expectations and competence level.

\section{MATERIALS AND Methods}

This was a cross-sectional study conducted on 70 interns willing to participate in the study at the end of internship period after taking clearance from the institutional Ethics committee. A 95 point questionnaire was prepared with the help of the logbook of interns with additional inputs from faculty of clinical specialties. Specialists from the departments of Medicine, Surgery, Ob-Gyn, Paediatrics, Ophthalmology and ENT prepared the list of competencies which they felt were essential to be acquired by a graduate by the end of internship duty. The questionnaire included competencies in examination skills, core performance skills, knowledge and attitude. After taking written informed consent, the interns were asked to mark their self perceived competence in the questionnaire as Competent/ not fully Competent/Not Competent in performing the competencies at the end of their internship period.

The three levels of competence were measured on a 3-point scale. The results were analyzed statistically.

\section{RESULTS}

\section{Competencies in Internal Medicine}

Out of 95 questions 8 were related basic recording of clinical parameters, 4 were pertaining to examination skills of medicine department, 13 questions identified the core competencies in medicine department and 27 questions were used to assess knowledge, attitude and skills of medicine department. In all 70 students were included in the study. Results of assessment of core competencies of students in internal medicine are shown in Fig-1.

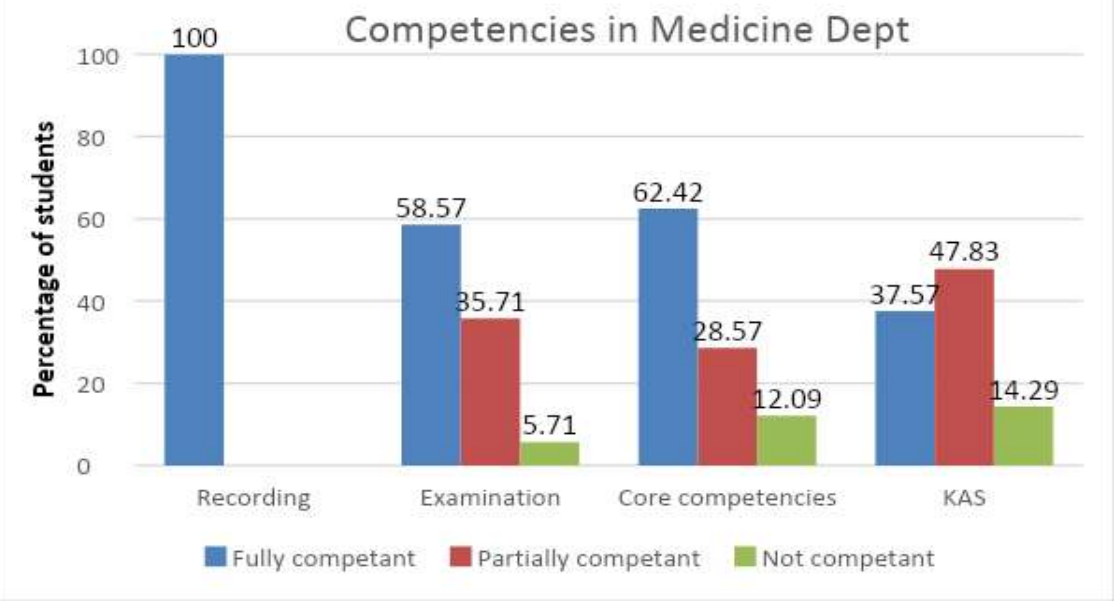

Fig-1: Competencies in medicine department

All the interns rated themselves as competent in recording basic clinical variables .Sixty percent interns rated themselves as fully competent in examination and core competencies. Only 8(11\%) interns self-rated as having poor examination skills and less than $15 \%$ interns rated themselves as poor in knowledge and attitude. It was noted that all the interns rated themselves as competent to administer intra muscular or intra venous drugs. All the interns also rated 
themselves as competent to interpret chest X-Ray or lab reports. On the other hand none of them self-rated to be fully competent to pass flatus tube. It was also noted that majority of the interns were not competent about all the first aid skills.

\section{Competencies in Surgery}

There were four questions about core competencies pertaining to surgical department, seven related to knowledge skills and attitude and one for examination skills of surgical department. Fig-2 shows results of competencies of interns in surgical department.

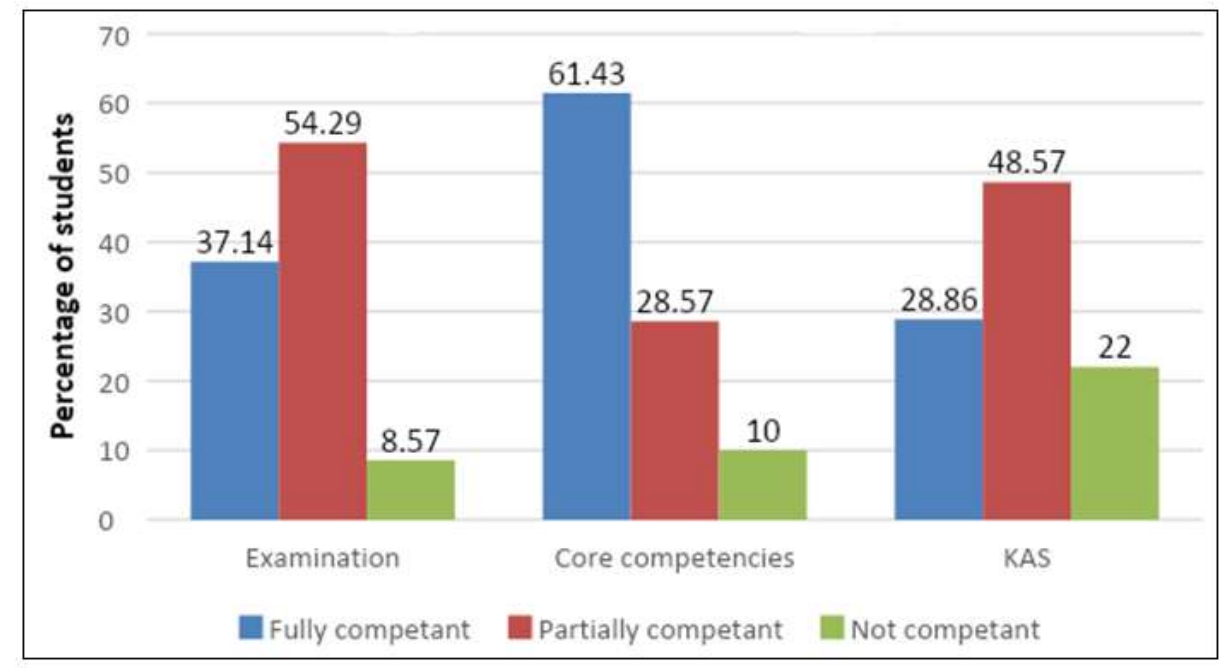

Fig-2: Competencies in Surgery Department

More than half of the interns self-rated that they were not fully competent in examination skills whereas more than $60 \%$ interns self-rated themselves good in core competencies. It was noted that all the interns rated themselves as competent to carry out sterile/ antiseptic skin dressing. While 26 interns rated themselves as good at performing rectal examination 38 were partially competent in doing it.

None of the interns had the knowledge about giving first aid to a gun shot wound, whether in head, chest or abdomen.

Competencies in ENT and Opthal department: Four questions were asked to assess the core competencies of ENT department. The results are shown in Fig-3.

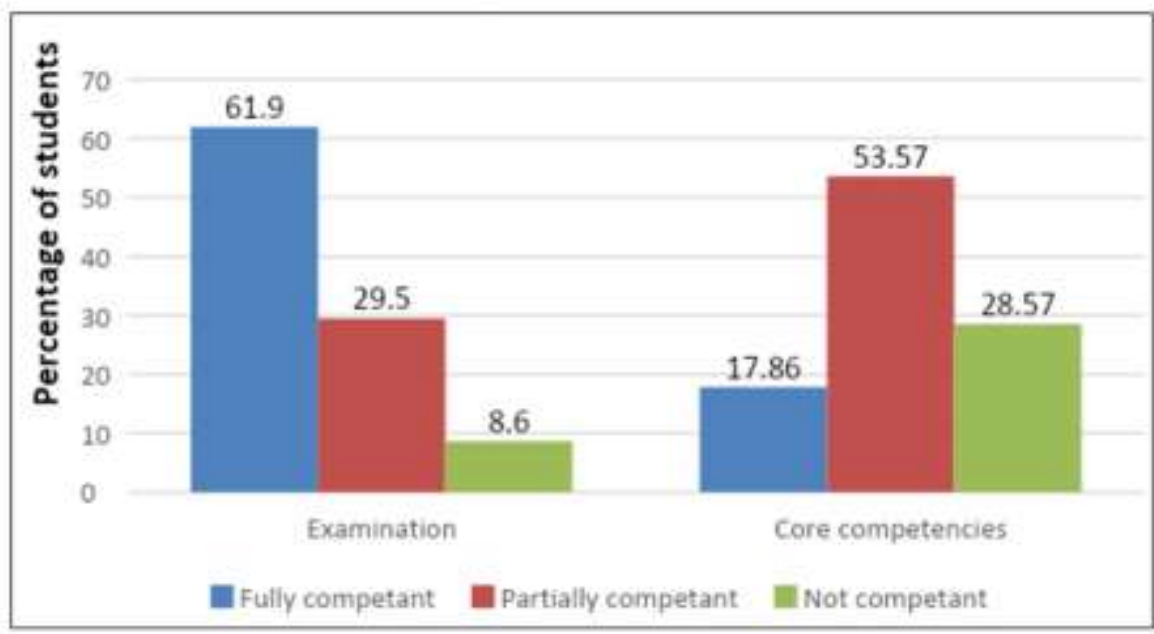

Fig-3: Competencies in ENT and Opthal department

Only one third interns rated themselves as good at examination skills pertaining to ENT and ophthalmology department. Similarly less than $20 \%$ interns rated themselves as good at core competencies related to ophthalmology and ENT. 
Competencies in Ob-Gyn department a set of 4 tasks were used to assess the examination skills of students. Fig 4 shows results of competencies of interns in Ob-Gyn department.

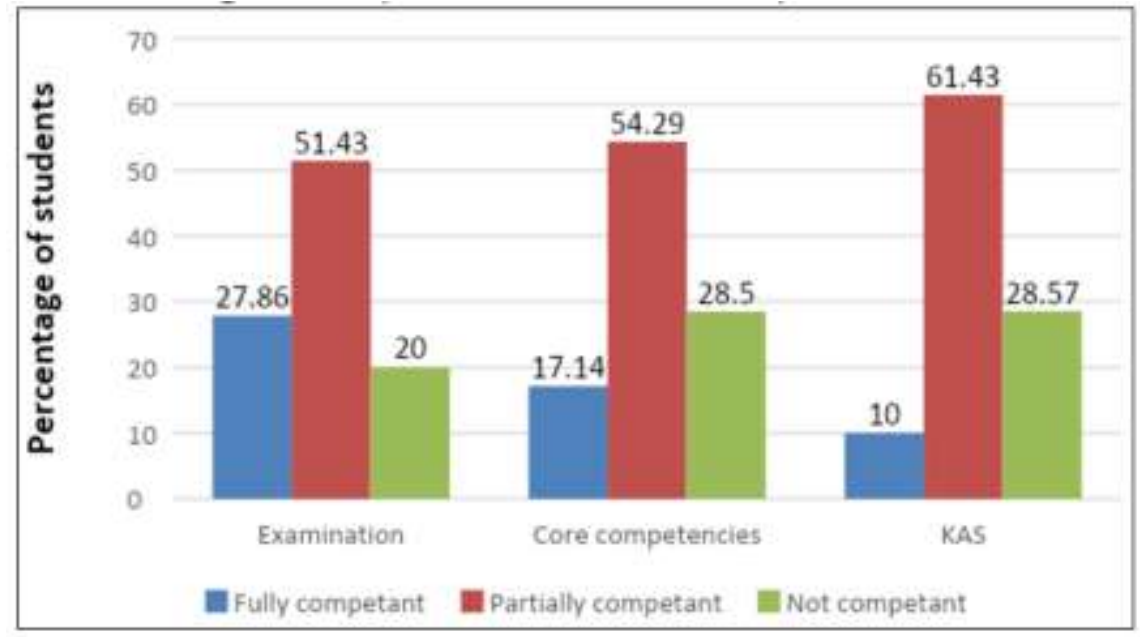

Fig-4: Competencies in Ob-Gyn department

Conducting a normal vaginal delivery was considered as core competency. Only 12 interns (27.8\%) rated themselves as fully competent to do so, while 51.4\% interns self-rated as having good examination skills in Ob-Gyn. As against this, none of the interns stated competence about Initial management of a case of bleeding per vaginum, and only $14(20 \%)$ of them rated themselves as competent in the initial management of a case of pre- eclampsia. Only $10 \%$ interns felt competent in knowledge and attitudinal skills.

Competencies of Pediatric dept: Three examination skills and six core competencies related to pediatric department were assessed. The results are shown in Fig-5.

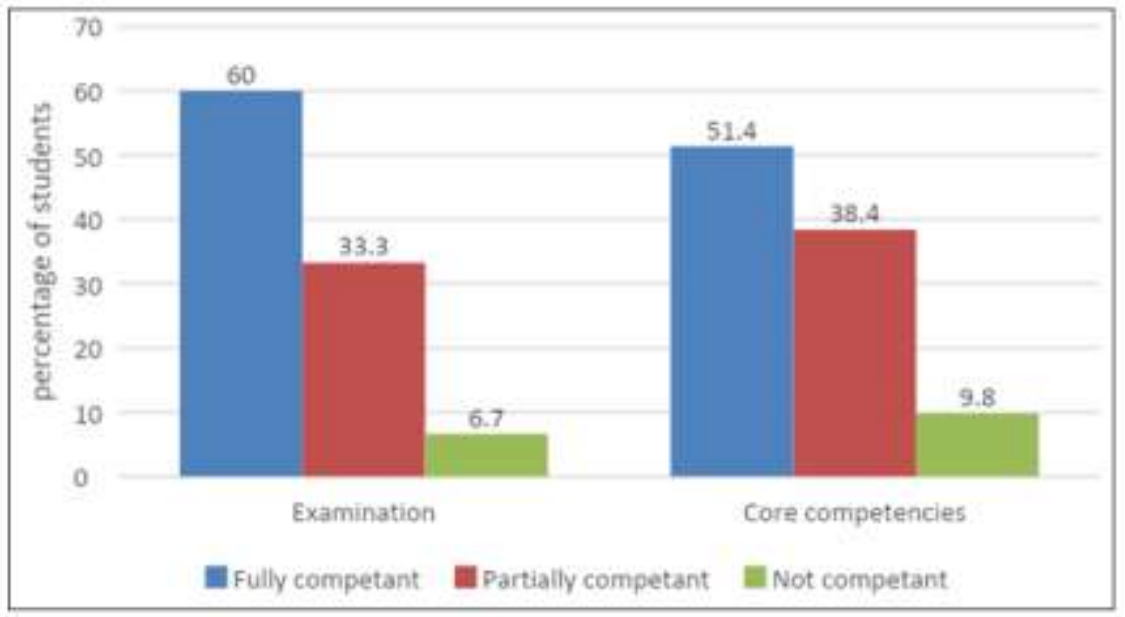

Fig-5: Competencies of Pediatric dept

It was observed that majority of the interns rated themselves as having good examination skills and core competencies.

Comparison of examination skills of various departments is shown in Fig-6. 


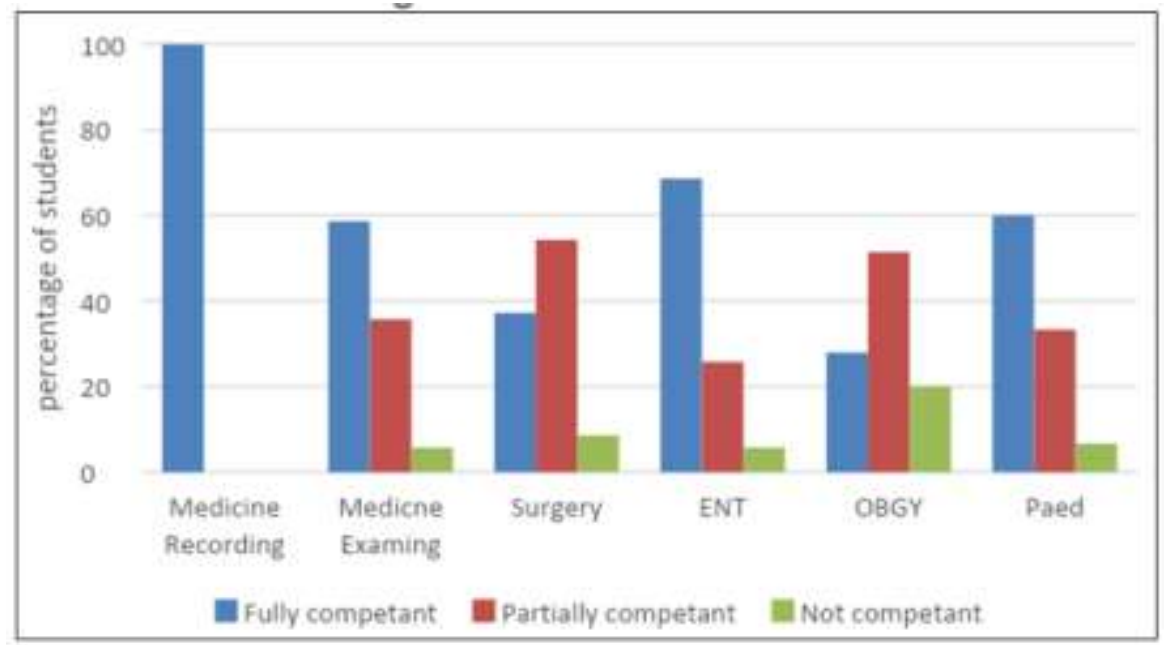

Fig-6: Examination Skills

It was observed that percentage of interns who self-rated themselves as having good examination skills was higher in department of internal medicine, ENT, ophthalmology and pediatrics as compared to the other departments. The difference was statistically significant $(\chi 2=23.25, \mathrm{p}<0.00011)$.As against this, the percentage of interns rating themselves as having poor examination skills was significantly more in Ob-Gyn department as compared to other departments. $(\chi 2$ $=15.88, \mathrm{p}<0.003)$.

Department wise comparison was also done to see percentage of interns self-rating their core competencies of each department (Fig-7).

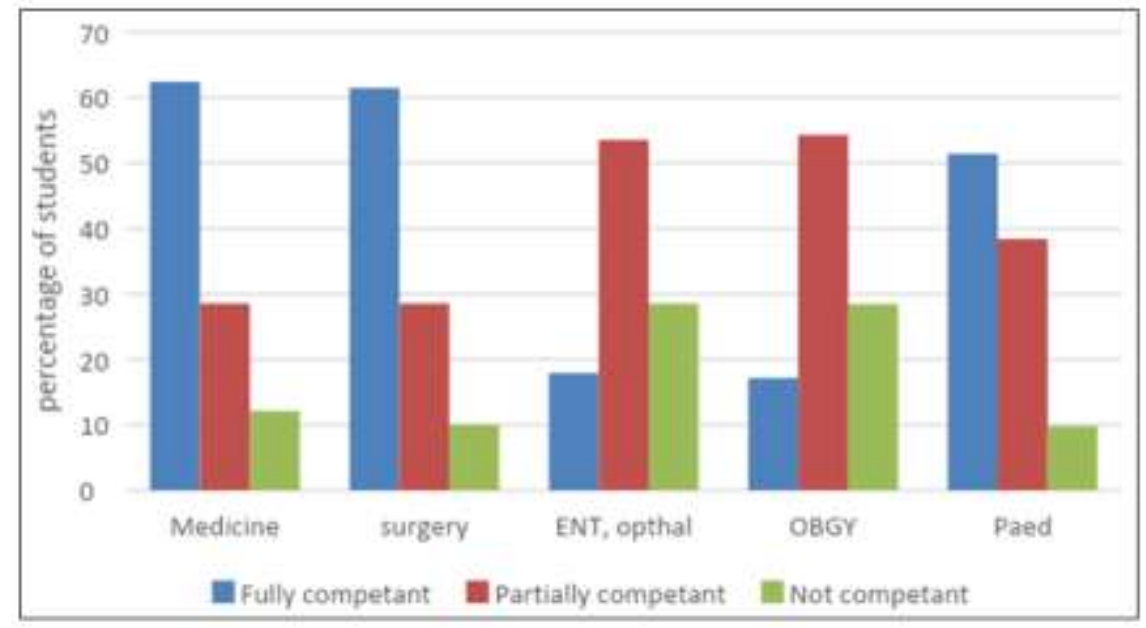

Fig-7: Core Competencies

It was observed that percentage of interns rating themselves as having good core competencies was significantly more in department of internal medicine and surgery as compared to that of ENT and Ophthal and Ob-Gyn $(\chi 2=49.55$, $\mathrm{p}<0.00001)$. As against this percentage of interns rating themselves as having poor core competencies was significantly more in ENT, ophthalmology and Ob-Gyn departments as compared to other departments. $(\chi 2=21.8, \mathrm{p}<0.0002)$.

\section{ObServations}

It is imperative that medical colleges produce graduates who have the requisite knowledge, skills and expertise to be an efficient physician of first contact while being globally relevant. To prepare a medical practitioner arguably takes more training time, examinations, and practices than any other profession [7]. This is necessitated by the need to produce competent health care practitioners possessing cognitive, technical, and personal skills for meeting the expectations of all stakeholders including the government, hospital management, patients and the society at large [8].

Competence is the key requisite that determines the preparedness of the medical graduate to handle a healthcare facility and his medical career. Epstein defines competence as the habitual and judicious use of communication, knowledge, skills, clinical reasoning, emotions, values and reflection in daily practice for the benefit of individuals and 
community being served. He also stated that competence is not an achievement but rather a habit of lifelong learning in which assessment plays an integral part in helping physicians identify and respond to their own learning needs [9].

In the present study we studied the self perceived assessment of competence of interns. This method of assessment has been used by other researchers to stimulate the introspective assessment of how adequately are physicians prepared to rise up to the challenge of unprecedentent dynamic arena of healthcare service rendering and delivery [10].

In the present study it was observed that on an average half of the interns (50.4\%) self-rated themselves as having good competencies, while less than ten percent $(9.3 \%)$ rated themselves as having poor examination skills.

A variety of studies have found that many graduates feel inadequately prepared for the role of junior doctor [1113] and criticisms that medical schools do not prepare graduates for early medical practice have been voiced many times. A study that explored UK junior doctors' views on preparedness in 2010, found that the level of agreement that medical school had prepared them well for work varied between medical schools and changed over time, ranging from $82 \%$ to $30 \%$ at one year, to $70 \%-27 \%$ (respectively) at three year's post graduation. Both medical schools and medical graduates have questioned preparation and preparedness for early medical practice [14].

In a study conducted in Germany, altogether $34.2 \%(n=215)$ of the participants reported that they felt well prepared for their up-coming medical career at the end of medical school, whereas $65.8 \%(n=413)$ of them felt inadequately prepared. In the initial descriptive analysis of the participants, they found that approximately $66 \%$ of the participating junior doctors did not feel well prepared for their job after finishing medical education [15]. This result supports the result of another German study by Jungbauer et al., [16] in which two thirds of the questioned alumni of seven medical universities in Germany reported to feel badly prepared for being a doctor. However, a study from UK found that only $23.8 \%$ of the 2005 cohort of UK medical school graduates disagreed that their medical school had prepared them well for the jobs they had undertaken during the first postgraduate year [17]. Cave et al., [18] found that $15 \%$ of respondents of their study felt poorly prepared by their medical school for starting work in the year 2005 , whereas, in the same year, $61 \%$ of Irish interns felt insufficiently or poorly prepared [19].

It was observed in the present study that percentage of students having good core competencies was significantly more in department of medicine and surgery as compared to that of ENT and Ophthalmology and OBGY. This variation in the competence may be because every department has its own learning culture. Knowledge and attitudinal skills were self-rated lower compared to the other skills.

\section{CONCLUSiOnS}

As stated in Goldacre et al., [17]. "most people starting a new professional job probably will, and probably should, feel unprepared to some extent". Nevertheless, this should not stop researchers and medical teachers from trying to provide the best preparation and education possible. This is especially important in the health care sector, where inexperience can lead to mistakes which affect patients' health [20, 21].

As medical teachers, it should be our aim to give equal opportunity to all the interns to acquire the requisite examination skills, teach them the core competencies and give them adequate experience in applying their knowledge, attitude and skills while tackling various situations under supervision. We should be paying special attention to imparting attitudinal skills to the budding doctors in the present times of increased violence against doctors. This will make them more competent and more confident as they step out as a graduate to work independently or as a postgraduate student.

With the Medical Council of India introducing key changes in the curriculum so as to create a competent medical graduate, the role of medical teachers will be better defined in carrying out this responsibility. Skills assessment should be conducted by every department at the end of internship posting. Skills assessment may be included in the post graduation entrance exam.

\section{Limitations Of THE STUDY}

1. The study was carried out in a private medical college with lesser workload as compared to government colleges so the competence levels may be different in comparison.

2. Since the questionnaire was filled up anonymously, we could not correlate the competence scores with the academic profile of the interns.

3. There is a possibility of wrong assessment.

4. The sample size was small to be representative of all the medical graduates.

Conflict of interest: None 


\section{REFERENCES}

1. Medical Council of India. $\quad$ Vision; $2015 . \quad$ Available from: http://www.mciindia.org/tools/announcement/MCI_booklet.pdf.

2. Jamkar, A., Bansal, P., Patrikar, S., \& Baxi, G. (2015). Expected surgical competencies of an Indian medical graduate: A gap analysis using a cross-sectional survey. Education for Health, 28(1), 4.

3. Gonnella, J. S., Hojat, M., Erdmann, J. B., \& Veloski, J. J. (1993). A case of mistaken identity: signal and noise in connecting performance assessments before and after graduation from medical school. Academic Medicine. 68(2 Suppl):S9-16.

4. Lypson, M. L., Frohna, J. G., Gruppen, L. D., \& Woolliscroft, J. O. (2004). Assessing residents' competencies at baseline: identifying the gaps. Academic Medicine, 79(6), 564-570.

5. Bansal, R. (2004). Need for strengthening of internship (rotatory housemanship) training in India. Education for Health, 17(3), 332-338.

6. Goel, A., Venkat, R., Kumar, A., Adkoli, B. V., \& Sood, R. (2010). Structured internship orientation programme for undergraduate students: Easy transition to clinical work. The National medical journal of India, 23(3), 160-162.

7. Adewale, A. A., \& Omar, A. (2012). Competence in medical practice as perceived by malaysian medical interns: A measurement invariance analysis. Journal of Education and Vocational Research, 3(7), 225-233.

8. Aggarwal, R., Grantcharov, T. P., \& Darzi, A. (2007). Framework for systematic training and assessment of technical skills. Journal of the American College of Surgeons, 204(4), 697-705.

9. Epstein, R. M. (2007). Assessment in medical education. New England journal of medicine, 356(4), $387-396$.

10. Marple, B. F. (2007). Competency-based resident education. Otolaryngologic Clinics of North America, 40(6), 1215-1225.

11. Watmough, S., O'Sullivan, H., \& Taylor, D. (2009). Graduates from a traditional medical curriculum evaluate the effectiveness of their medical curriculum through interviews. BMC Medical Education, 9(1), 64.

12. Bojanić, K., Schears, G. J., Schroeder, D. R., Jenkins, S. M., Warner, D. O., \& Sprung, J. (2009). Survey of selfassessed preparedness for clinical practice in one Croatian medical school. BMC Research Notes, 2(1), 152.

13. Guest, A. R., Roubidoux, M. A., Blane, C. E., Fitzgerald, J. T., \& Bowerman, R. A. (1999). Limitations of student evaluations of curriculum. Academic radiology, 6(4), 229-235.

14. Goldacre, M. J., Taylor, K., \& Lambert, T. W. (2010). Views of junior doctors about whether their medical school prepared them well for work: questionnaire surveys. BMC medical education, 10(1), 78.

15. Ochsmann, E. B., Zier, U., Drexler, H., \& Schmid, K. (2011). Well prepared for work? Junior doctors' selfassessment after medical education. BMC medical education, 11(1), 99.

16. Jungbauer, J., Alfermann, D., Kamenik, C., \& Braehler, E. (2003). Psychosocial skills training unsatisfactory results from interviews with medical school graduates from seven German universities. Psychotherapie, Psychosomatik, medizinische Psychologie, 53(7), 319-321.

17. Goldacre, M. J., Taylor, K., \& Lambert, T. W. (2010). Views of junior doctors about whether their medical school prepared them well for work: questionnaire surveys. BMC medical education, 10(1), 78.

18. Cave, J., Woolf, K., Jones, A., \& Dacre, J. (2009). Easing the transition from student to doctor: how can medical schools help prepare their graduates for starting work?. Medical teacher, 31(5), 403-408.

19. Abuhusain, H., Chotirmall, S. H., Hamid, N., \& O'Neill, S. J. (2009). Prepared for internship?. Irish medical journal, 102(3), 82-84.

20. Heffner, J. E., Ellis, R., \& Zeno, B. (2005). Safety in training and learning in the intensive care unit. Critical care clinics, 21(1), 129-148.

21. Posner, K. L., \& Freund, P. R. (2004). Resident training level and quality of anesthesia care in a university hospital. Anesthesia \& Analgesia, 98(2), 437-442. 